\title{
Mining disease-resistance genes in roses: functional and molecular characterization of the $R d r 1$ locus
}

\author{
Diro Terefe-Ayana ${ }^{\dagger}$,Aneela Yasmin ${ }^{\dagger}$, Thanh Loan Le, Helgard Kaufmann, Anja Biber, Astrid Kühr, \\ Marcus Linde and Thomas Debener*
}

Institute for Plant Genetics, Leibniz University Hannover, Hannover, Germany

Edited by:

Diego Rubiales, Consejo Superior de

Investigaciones Cientificas, Spain

\section{Reviewed by:}

Anna Maria Mastrangelo, CRA-Centro

di Ricerca per la Cerealicoltura, Italy

Noel Ferro Diaz, University of Bonn,

Germany

Teresa Millan, Universidad de Cordoba, Spain

\section{*Correspondence.}

Thomas Debener, Institute for Plant Genetics, Leibniz University Hannover, Herrenhäuser Str. 2, D-30419

Hannover, Germany.

e-mail:debener@genetik.uni-hannover. de

${ }^{+}$Diro Terefe-Ayana and Aneela Yasmin have contributed equally to this work.
The interaction of roses with the leaf spot pathogen Diplocarpon rosae (the cause of black spot on roses) is an interesting pathosystem because it involves a long-lived woody perennial, with life history traits very different from most model plants, and a hemibiotrophic pathogen with moderate levels of gene flow. Here we present data on the molecular structure of the first monogenic dominant resistance gene from roses, $R d r 1$, directed against one isolate of $D$. rosae. Complete sequencing of the locus carrying the $R d r 1$ gene resulted in a sequence of 265,477 bp with a cluster of nine highly related TIR-NBS-LRR (TNL) candidate genes. After sequencing revealed candidate genes for Rdr1, we implemented a gene expression analysis and selected five genes out of the nineTNLs. We then silenced the wholeTNL gene family using RNAi (Rdr1-RNAi) constructed from the most conserved sequence region and demonstrated a loss of resistance in the normally resistant genotype. To identify the functional TNL gene, we further screened the five TNL candidate genes with a transient leaf infiltration assay. The transient expression assay indicated a singleTNL gene (muRdr1 H), partially restoring resistance in the susceptible genotype. Rdr1 was found to localize within the muRdr1 gene family; the genes within this locus contain characteristic motifs of active TNL genes and belong to a young cluster of $R$ genes. The transient leaf assay can be used to further analyze the rose black spot interaction and its evolution, extending the analyses to additional $R$ genes and to additional pathogenic types of the pathogen.

Keywords: Rosa, woody plant, Diplocarpon rosae, transient assay, Rdr1, disease

\section{INTRODUCTION}

Black spot caused by the hemibiotrophic ascomycete Diplocarpon rosae Wolf is the most devastating disease that impacts field-grown roses (Drewes-Alwarez, 2003; Horst, 2008). Strategies to control the disease include the application of agrochemicals or the introgression of disease-resistance genes. Though roses are important ornamental crops with high economic importance, little progress has been made in the field of resistance breeding because genetic information about important disease-resistance traits is scarce (Debener and Linde, 2009).

Analyses of the genetic variability of both $D$. rosae and roses indicate that the interaction follows a so-called "gene for gene" interaction (Debener et al., 1998). To date, two monogenic dominant genes providing race-specific resistance to black spot have been genetically characterized (Debener et al., 1998; Whitaker et al., 2010a). Most published reports discuss $R d r 1$, which confers resistance to $D$. rosae isolates from races one to five and which was finemapped to the telomeric ends of rose chromosome 1 (Kaufmann et al., 2003; Biber et al., 2010). Rdr1 was introgressed into cultivated roses from the diploid Asian species Rosa multiflora and leads to an arrest of mycelia development 2-3 days after germination of conidia. The resistance phenotype is accompanied by a hypersensitive response (HR; Gachomo and Kotchoni, 2010), although it is difficult to separate this from cell death that occurs at later stages of compatible interactions.
Although 11 pathogenic races of Diplocarpon have been recently described, data on the diversity and population dynamics of this pathogen indicate a relatively slow spread of new pathogenic races within rose populations (Lühmann et al., 2010). This is in contrast to wind-borne pathogens, for example, powdery mildews. Therefore, monogenic disease-resistance genes are an interesting option for the development of black spot resistant rose cultivars.

The majority of $R$ genes characterized so far encode NB-LRR proteins involved in the so-called "effector-triggered immunity" that directly or indirectly interact with pathogen-derived effector molecules (Dodds and Rathjen, 2010). There are two major groups of NBLRR proteins: the CC-NB-LRRs (CNLs), which have an N-terminal coiled-coil domain, and the TIR-NB-LRRs (TNLs), which have an $\mathrm{N}$-terminal domain with similarity to Toll and the human interleukin receptor (Eitas and Dangl, 2010). Whereas CNLs occur in both monocots and dicots, TNLs only occur in dicots, but both groups share overlapping, but not identical, signal transduction pathways. Most NB-LRR proteins are assumed to directly or indirectly recognize the presence of an effector molecule via the highly variable LRR domain. Less variability occurs within the CC/TIR and NB domains, which function in signal transduction and intermolecular communication. More than $50 \%$ of all NB-LRR coding genes occur in clusters of more or less tightly linked genes with very heterogeneous patterns of evolution characterized by either rapidly evolving type I genes or slowly evolving type II genes (McHale et al., 2006). 
Though a large number of NB-LRR coding genes are found in long-lived woody perennials, only very few have been analyzed in more detail, and no NB-LRR gene has been functionally characterized in a woody perennial. It has been proposed that many of the NB-LRR gene families in various woody plants are phylogenetically young (Yang et al., 2008); however, little is known about the phylogenetic processes shaping the diversity of NB-LRRs in woody perennials compared to well-studied annuals.

Here we present a strategy for a functional test of a large number of $R$ gene candidates from non-model species that are difficult to transform by conventional methods. Furthermore, we present data on the structure of the $R d r 1$ locus harboring the $R d r 1$ disease-resistance gene as a basis for future applications in resistance breeding in roses and studies on the evolution of the rose black spot pathosystem.

\section{MATERIALS AND METHODS PLANT MATERIAL, BAC CLONES, AND FUNGAL ISOLATES}

The R. multiflora hybrids $88 / 124-46(2 \mathrm{n}=2 \mathrm{x}=14)$ and $91 / 100-5$ $(2 \mathrm{n}=4 \mathrm{x}=28)$ carrying the $R d r 1$ gene (Debener et al., 1998) and the hybrid tea rose Pariser Charme $(2 \mathrm{n}=4 \mathrm{x}=28)$ were cultivated under semi-controlled conditions in a greenhouse as described previously (Biber et al., 2010). Biber et al. (2010) previously constructed the BAC clones utilized in this study.

The black spot isolates DortE4 (race 6; Whitaker et al., 2010b) was maintained on leaves of the rose variety Pariser Charme as described by Debener et al. (1998). Conidia were washed from infected leaves with sterile distilled water and adjusted to defined densities with a hemocytometer.

\section{DNA AND RNA ISOLATION}

For DNA isolation, about $70 \mathrm{mg}$ of young leaf tissue was dried, and DNA was isolated using the Nucleospin ${ }^{\circledR}$ Plant II kit (MachereyNagel GmbH \& Co. KG, Dueren, Germany) according to the manufacturer's instructions. BAC DNA was isolated by alkaline lysis (SDS) from $500 \mathrm{ml}$ of bacterial culture grown overnight according to Sambrook and Russell (2001). All small-scale plasmid isolations were carried out using Nucleospin ${ }^{\circledR}$ Plasmid kits (Macherey-Nagel GmbH \& Co. KG, Dueren, Germany) according to the manufacturer's instructions. For RNA extraction, plant tissues (30-50 mg) were frozen in liquid nitrogen and ground to a fine powder in a bead mill. Extractions were performed using the Invisorb ${ }^{\circledR}$ Spin Plant RNA Mini Kit (Invitek, Berlin, Germany) according to the manufacturer's instructions. The contaminating DNA was removed from the extracted RNA using the DNase free kit from Ambion (Cambridgeshire, UK) as recommended by the manufacturer. The quality of both DNA and RNA was checked on agarose gels, and quantification was performed photometrically at 260 and $280 \mathrm{~nm}$.

\section{SEQUENCING AND DE NOVO ASSEMBLY}

The physical map of $R d r 1$ was confined to four overlapping BAC clones (Biber et al., 2010). Escherichia coli DH10B cells carrying the BAC clones were delivered in stab agar to Cogenics (Cogenics Ltd., Morrisville, NC, USA), which performed 454 FLX sequencing with $50 \%$ of a full run. Sequences were automatically clipped for adaptors and primer sequences and assembled with Newbler assembler by Cogenics (Cogenics Ltd., Morrisville, NC, USA). After the 454 sequencing and de novo assembly, the BAC clone sequences did not completely assemble into the desired large fragment. Therefore, subclones were established from DNA of each BAC clone as described in a later section. The subclones were transferred onto new 96-well microtiter plates containing stab agar and delivered to commercial sequencing services for plasmid DNA preparation and Sanger sequencing. For some of the subclones generated in the pBSKII-vector (Stratagene, La Jolla, CA, USA), plasmid DNA was prepared by a standard alkaline lysis method (Sambrook and Russell, 2001), and sequencing was performed with a Licor DNA-Analyzer Gene Read IR 4200 (LI-COR, Lincoln, NE, USA) using 6\% Polyacrylamide gels (National Diagnostics, Atlanta, GA, USA). Fluorescent-labeled standard M13 primers and a Thermo Sequenase cycle sequencing kit (USB/Affymetrix, Santa Clara, CA, USA) were utilized in the sequence reaction mixtures. All of the sequences generated were assembled with SeqMan (DNASTAR, Madison, WI, USA) and ContigExpress (Invitrogen, La Jolla, CA, USA) software. The final assembly was checked by comparison of an experimentally determined restriction enzyme fingerprint for each BAC clone with that of computationally generated fingerprints.

\section{GENE PREDICTION AND ANNOTATION}

Bioedit (Hall, 1999) was used for viewing and editing of sequences. Gene prediction and annotation was done using the gene prediction programs FGENESH and GENSCAN (http://www.softberry. com; http://genes.mit.edu/GENSCAN.html). To complement the gene prediction programs and determine sequence similarity, the whole sequence was fragmented in silico into 1-kb fragments with 200-bp overlaps and subjected to BLASTn and BLASTx searches (Altschul et al., 1997) against the GenBank database. Furthermore, the protein domains of the gene clusters on the BAC sequence were determined using Pfam version 23.0 (Finn et al., 2008), SMART 6 (Letunic et al., 2009), and conserved domain database (CDD) v2.16 (Marchler-Bauer et al., 2007). Sequences that were identical to known genes in GenBank were assigned that gene name.

\section{GENERATION OF SUBCLONES}

In addition to the complete sequencing of the BAC clones, single TNL candidate genes were subcloned by either partial or complete enzymatic digestion of BAC DNAs. Five micrograms of DNA was partially digested with $4 \mathrm{U}$ of Sau $3 A 1$ for $15 \mathrm{~min}$ at $37^{\circ} \mathrm{C}$. Restriction fragments were size-separated on $0.8 \%$ agarose gels, and bands with $\sim 7-12 \mathrm{~kb}$ size were isolated using the QIAquick gel extraction kit (Qiagen GmbH, Hilden, Germany). For complete digestion of BAC clones, $10 \mu \mathrm{g}$ of BAC DNA was digested with $10 \mathrm{U}$ of the appropriate restriction enzymes overnight at $37^{\circ} \mathrm{C}$, and fragments were isolated as described above.

Fragments were cloned into the binary vector pBINPLUS (van Engelen et al., 1995) or the pBSKII-vector (Stratagene, La Jolla, CA, USA), which were pre-digested with compatible restriction enzymes and dephosphorylated with Shrimp Alkaline phosphatase (MBI Fermentas GmbH, St. Leon-Rot, Germany) according to the manufacturer's instructions. Ligations were performed in a total volume of 10-15 $\mu \mathrm{l}$ containing 15-30 ng of dephosphorylated vector, 30-90 ng of insert, ATP to a final concentration of $1 \mathrm{mM}, 1 / 10$ volume of buffer, and 2.5 Weiss units of T4 DNA ligase and were incubated at $14^{\circ} \mathrm{C}$ overnight. 
One to two microliters of the ligation reaction mixture was mixed with $40 \mu \mathrm{l}$ of electro-competent E. coli (DH10B) or Agrobacterium cells, and the cells were pulsed using BioRad Micropulser with the EC2 program ( $2.5 \mathrm{kV}$ for $0.2 \mathrm{~cm}$ cuvettes, $25 \mu \mathrm{FD}, 400 \Omega$, Pulse time 8-12 ms) and further processed according to Sambrook and Russell (2001). Positive clones were picked and confirmed through PCR using general primers for the TNL or the standard M13 primers (Table A2 in Appendix). Some of the subclones were transferred onto new 96-well microtiter plates containing stab agar, delivered to sequencing companies for professional sequencing and then used in the complete assembly of the BAC clones as described earlier.

\section{SSR-PCR FOR CLONE VERIFICATION}

Verification of the TNL subclones and analyses of cDNA samples for the expression of individual genes was conducted with primer pair Rd1LRR_F and Rd1LRR_R as described in Terefe and Debener (2010). Rd1LRR primers are markers based on simple sequence repeats (SSR) in rose TNLs.

\section{EXPRESSION ANALYSES}

Total RNA (300-500 ng) was used to synthesize first-strand cDNA using random primers and the high-capacity cDNA reverse transcription kit (Applied Biosystems, Karlsruhe, Germany). The quality of the cDNA and potential contaminations with genomic DNA was checked via RT-PCR using primer pairs for rose actin, which flank an intron. To evaluate the expression of individual TNL candidate genes, PCR was performed on first-strand cDNA with the specific primer pairs listed in Tables A1 and A2 in Appendix.

\section{TRANSIENT EXPRESSION ASSAY, GENE SILENCING, AND STATISTICAL ANALYSIS}

Agroinfiltrations into rose leaves were performed as described in Yasmin and Debener (2010) with minor modifications. The leaves of rose varieties Pariser Charme and 91/100-5 were infiltrated by Agrobacterium suspensions harboring single TNLs at $\mathrm{OD}_{600}=1.5$ and challenged by D. rosae (races 6 and 7) at the same time as TNL infiltration. The spore concentrations were adjusted to $5 \times 10^{2}-10^{5}$ conidia/ml as described by Dohm et al. (2001). Infiltrated samples were incubated at $22^{\circ} \mathrm{C}$ in the dark, and the samples were collected for fluorescence microscopy 4 days after infiltration/inoculation. Inoculated leaves were stained with Aniline blue after clearing in $1 \mathrm{M} \mathrm{KOH}$ solution for $15 \mathrm{~min}$ at $121^{\circ} \mathrm{C}$ as described by Hood and Shew (1996). The samples were examined under a fluorescent microscope (Zeiss epifluorescence microscope-excitation 450$490 \mathrm{~nm}$, diachronic mirror $510 \mathrm{~nm}$, barrier $520 \mathrm{~nm}$ ), and fungal growth was scored as the number of hyphal clusters per infiltration site. Hyphal clusters are defined as networks of branched hyphae that develop after germination of conidia within the infiltrated area.

A double-stranded cDNA sequence of $1098 \mathrm{bp}$ from the most conserved exon 2 region of the TNLs was inserted between two $35 \mathrm{~S}$ inverted promoters in a p9U10-RNAi vector to trigger the production of an Rdr1-RNAi effect, resulting in gene silencing (DNA-Cloning Services e.K., Hamburg, Germany).Agrobacterium suspensions harboring the Rdr1-RNAi were infiltrated into leaves of Pariser Charme and 91/100-5 varieties and challenged by $D$. rosae (race 6). Further analysis and data collections were made as previously described.
Statistical evaluation of the infiltration experiments was conducted with the R-software package (R Development Core Team, 2009). For each experiment, 20 infiltration sites were recorded, and tests for differences between treatments were conducted with the Kruskal Wallis and the Wilcoxon procedures. In those cases where the Kruskal Wallis test indicated significant differences among treatments, pair-wise comparisons were conducted with the Wilcoxon rank sum test.

\section{RESULTS \\ THE Rdr1 LOCUS CARRIES NINE HIGHLY SIMILAR TNL GENES}

The black spot resistance gene $R d r 1$ is a monogenic dominant gene introgressed into diploid garden roses from $R$. multiflora and had been previously localized at the telomeric end of rose linkage group 1. High-resolution mapping confined the region around $R d r 1$ to an interval defined by four overlapping BAC clones (Biber et al., 2010). These four clones (clones 29O3, 94G8, 20F5, and 69E24) were submitted to next generation sequencing in pairs of two overlapping clones through a professional sequencing service. A total of 467,700 sequences from $50 \%$ of a 454 GS FLX run provided 227,395 sequences, with an average length of $241 \mathrm{bp}$ and a theoretical sequence coverage of 137 times. These sequences were assembled by the Newbler software into 128 contigs. Highly similar repeats present on the contig made a reliable and complete assembly based on the 454 sequences alone impossible; therefore, we generated 550 additional sequence reads, using the Sanger method, from completely digested and partially digested subclones of more than $2 \mathrm{~kb}$ and from fragments generated by primer walking to fill the remaining gaps. This resulted in a complete sequence of $265,477 \mathrm{bp}$ with an average GC content of 39\%. The complete 265, 477-bp has been deposited in the GenBank database under accession number HQ455834.

By analyses with BLAST, Pfam, and SMART6, 47 genes were predicted from the sequence, 40 of which had significant matches to GenBank entries (Figure 1; Table 1). Among these 40 predicted genes, nine sequences distributed over $204 \mathrm{~kb}$ had highly significant similarities to resistance genes of the TIR-NBS-LRR (TNL) type. Among the other sequences we found 10 transposable-elements and sequences with similarities to transcription factor B3, AAA type ATPases, and protein kinases (Table 1). However, because the protein kinases are located beyond the recombination breakpoints present on the contig, the nine TNL sequences remained the most likely candidates for $R d r 1$. We therefore designated these genes as $m u R d r 1 A$ to $m u R d r 1 I$, in which "mu" stands for the species name of the source of the sequence ( $R$. multiflora) and "A" to "I" indicates the order of the Rdr1 TNL on the sequenced contig. The predicted amino acid sequence for the nine TNLs has been deposited in the GenBank database under accession numbers AEE43925 to AEE43933. As shown previously, a microsatellite marker was found in the expressed part of exon 4 of $m u R d r 1 A, C$, and $H$, and this marker co-segregates with the functional $R d r 1$ gene without recombination (Terefe and Debener, 2010; Figure 1).

Based on the predicted transcriptional start and stop codons, the size of the nine $m u R d r 1$ genes, including introns, varied from 4085 to $5920 \mathrm{bp}$. Only $m u R d r 1 D$ differed from this due to a transposableelement insertion of 6957 bp within intron 1, resulting in a total length of $11,590 \mathrm{bp}$. Six of the nine $m u R d r l$ genes $(A, C, D, E, F, H)$ 


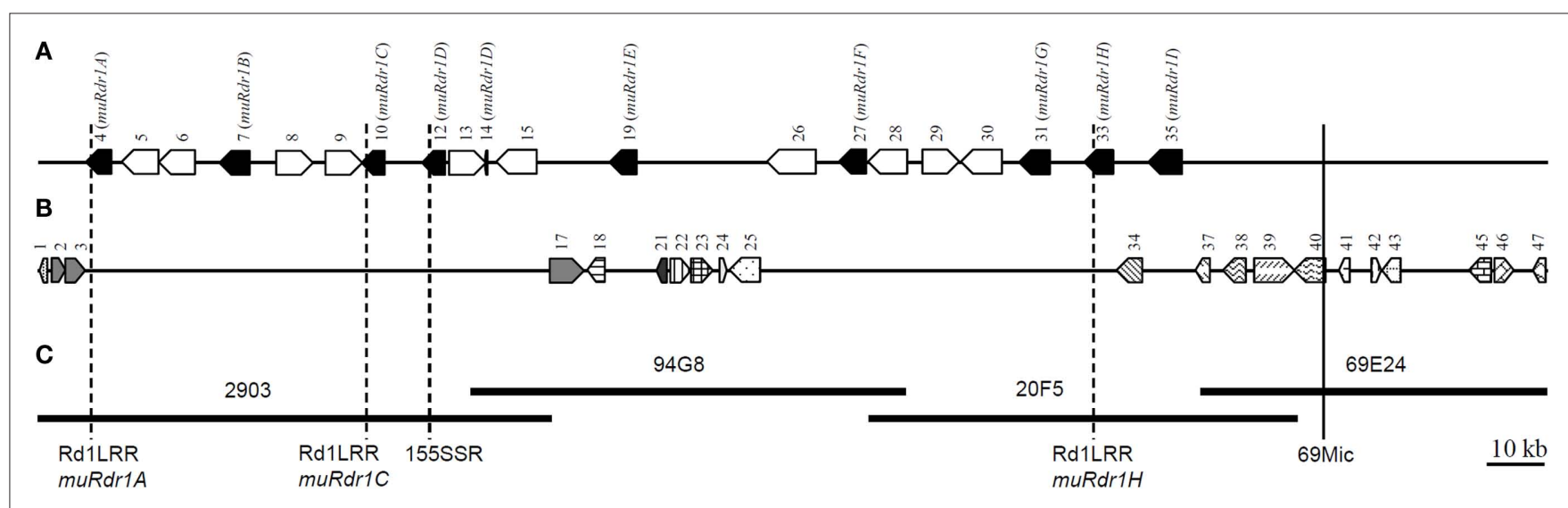

FIGURE 1 | Physical positions of the Rdr1 gene region and schematic representation of positions of predicted genes in the $R$. multiflora genotype. (A) Nine TNLs (black pentagon) and 10 transposable-elements (unfilled pentagon). (B) Other genes distributed along the Rdr1 region. (C) The completely sequenced four overlapping BAC clones carrying the Rdr1 gene.
The broken-line indicates Rdr1-linked SSR markers. The vertical unbroken line indicates recombination break point (69Mic) on the right side of the region. Numbers on each pentagon refer to the genes as described in Table 1. Predicted genes without any similarity in the GenBank database are not represented. have four exons and three introns, two $(m u R d r 1 B$ and $G)$ have two additional introns and one ( $m u R d r 1 I$ ) has only three exons and two introns (Figure 2). The intron-exon structure reflects the domain structure of typical TNL proteins in that the first exon contains the TIR domain, the second exon contains the NBS domain and the forth (or in case of TNL-muRdr1I, the third exon) contains an LRR domain. The most closely related TNL sequences from other species, with a proven function as resistance genes, are CMR1 from Phaseolus vulgaris (Seo et al., 2006) and the $\mathrm{N}$ gene from tobacco (Whitham et al., 1994), with 44 and 36\% sequence identity at the amino acid level, respectively. The overall amino acid identity among the nine members of the $m u R d r 1$ TNL-family was between 78 and 99\% (Table 2). Conserved within all of the nine muRdrl genes were motifs characteristic for functional TNL genes; for example the Kinase 1a (P-loop), kinase 2, and Kinase 3a motifs of the NBS domain (Traut, 1994; van Ooijen et al., 2008) as well as motifs 2, 3, 4, and 5 and the HD motif (Hammond-Kosack and Jones, 1997; Figures 3A,B). This confirms their putative function as TNL resistance genes; however, none of the nine genes could be excluded as the functional $R d r 1$ gene based on a lack of conservation in these motifs.

\section{FIVE OF THE NINE TNLS ARE EXPRESSED IN LEAVES AND PETALS}

Previous analyses had shown that the Rdrl gene is active and confers resistance in both rose leaves and petals (Debener et al., 1998); therefore, we analyzed expression of all nine TNLs in different rose organs, as non-expressed copies of the muRdrl gene family can be excluded as likely Rdrl candidates. PCR primers were designed based on the variable parts of exons three and four (Table Al in Appendix) and tested for specificity with cloned individual members of the gene family. In addition, a primer pair for an expressed SSR marker in exon 4 was used (Terefe and Debener, 2010). RT-PCR was conducted on cDNA from leaves and petals of genotypes 88/124-46 and 91/100-5, which both express Rdr1. In summary, muRdrlA, $C, G, H$, and $I$ were expressed in both leaves and petals, whereas muRdr1D, E, and $F$ expression was undetectable. One of the TNL genes, $m u R d r 1 B$, was not detectable in petals of genotype 88/124-46 and not at all in genotype 91/100-5 (Table 3). Therefore, $m u R d r 1 B, D, E$, and $F$ were excluded as likely candidates for $R d r 1$.

\section{Rdr1 IS A MEMBER OF THE muRdr1 GENE FAMILY}

To get additional information on the role of the muRdr1 genes, we performed a transient silencing experiment of the whole gene family. To accomplish this, we used a construct based on the vector p9U10-RNAi (DNA-Cloning Services e.K., Hamburg, Germany). We used a 1098-bp fragment from the highly conserved NBS region of exon 2 of $m u R d r 1 H$ which shares an overall similarity of $86-96 \%$ to all other $m u R d r 1$ genes (local similarities over stretches $>100 \mathrm{bp}$ were more than 95\%). This recently designed vector induces RNAibased gene silencing by inducing the transcription of large inserts directed by two flanking $35 \mathrm{~S}$ promoters in opposite orientations.

Stable transformation in rose is feasible but suffers from low efficiency and a long period before inoculation-ready plants can be obtained (Dohm, 2003). As previous experiments had shown that the rose/black spot interaction remains unaltered if conidia are infiltrated into rose tissues at the same time as Agrobacteria (unpublished data), transient infiltration experiments were conducted to silence the $m u R d r 1$ gene family.

Using the rose genotypes Pariser Charme and 91/100-5, we exposed tissues either with only conidia of DortE4 (compatible interaction with Pariser Charme, incompatible interaction with 91/100-5), with conidia of DortE4 together with a control plasmid expressing a GUS-intron or with conidia of the black spot isolate DortE4 together with Rdr1-RNAi, the silencing construct. In agreement with earlier experiments, the resistant genotype $91 / 100-5$ did not allow growth of hyphal clusters except in 1 out of 20 infiltration sites; the one exception showed only a single cluster (Figure 4). The co-infiltration with Agrobacteria harboring the GUS-intron control plasmid allowed a small number of clusters to grow; however, these clusters had only a few hyphae and were distinct in morphology from those of the clusters growing in fully susceptible conditions (Figure 5A). In contrast, the infiltration of conidia 


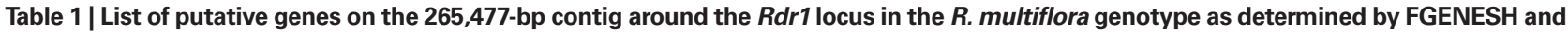
GENSCANa.

No. Position on the contig (bp)

P

1 152-1508

2

3

4

5

6
Similarity as revealed by BLASTx

(similar to GenBank accession number)

2148-4619

4949-8469

8597-13018

14663-21191

21192-27523

31861-37192

41617-48142

50202-56680

56880-60964

64274-65871

67461-71530

71531-78487

78507-79050

80614-87779

88120-89200

89855-95874

96748-99858

100820-105639

105836-108876

109031-110810

110980-114589

114616-118400

119769-121057

121735-127184

128519-137108

141304-146034

146035-152952

155448-161924

162463-169678

172839-178219

181050-182307

184220-189278

189875-194468

195401-201320

201731-202464

203727-206274

208583-212594

213804-220906

221077-226599

228916-230843

234625-236345

236499-239809

240805-251314

251877-255855

255956-259358

263037-265313
Vacuolar protein sorting-associated protein (ABA46760)

Transcription factor B3 (ABN06173)

Transcription factor B3 (ABD32483)

TIR-NBS-LRR (ABH07384)

Retroelement (ABF96803)

Retroelement (ABF96803)

TIR-NBS-LRR (ABH07384)

Copia (BAA97087)

Putative copia like polyprotein (AAS79613)

CMR1 (ABH07384)

None

CMR1 (ABH07384)

Retrotransposon protein (ABA95230)

TIR (EF455016)

Gag-protease-integrase (BAG72096)

None

Transcription factor B3 (ABN06173)

3-dehydroquinate dehydratase (AAS90325)

CMR1 (ABH07384)

None

GAG-POL precursor (BAD18985)

Prolyl 4-hydroxylase alpha (BAB02864)

Aminotransferase-like (BAD81757)

WUSCHEL protein terminator (Q8LL11)

Inosine-5'-monophosphate dehydrogenase (NP_173085)

Retrotransposon gag protein (ABD63142)

CMR1 (ABH07384)

copia-type pol polyprotein (BAA97087)

Putative copia like polyprotein (AAS79613)

Gag-protease-integrase (XP_002276920)

CMR1 (ABH07384)

None

CMR1 (ABH07384)

3-dehydroquinate dehydratase (AAS90325)

CMR1 (ABH07384)

None

Avr9/Cf-9 rapidly elicited protein (AAV92898)

AAA type ATPase (CAL52837)

Yellow stripe-like protein (BAF48331)

RAB GTPase activator (NP_190504)

6-phosphogluconolactonase (ABG73467)

Ubiquitin fusion protein (AAZ20285)

Homeobox-leucine zipper protein (Q651Z5)

None

TOPLESS-RELATED2 (NP_188306)

Structural maintenance of chromosome3 (CAD59411)

Serine/threonine protein kinase (AAL87457)

Evalue

$8 e^{-40}$

$1 \mathrm{e}^{-12}$

$8 e^{-10}$

0.0

0.0

0.0

0.0

0.0

0.0

0.0

$-$

0.0

$9 e^{-79}$

0.0

$3 e^{-179}$

$-$

$1 e^{-05}$

$4 \mathrm{e}^{-08}$

0.0

$-$

$1 e^{-31}$

$3 e^{-12}$

$3 e^{-22}$

$3 e^{-23}$

$8 e^{-34}$

0.0

0.0

0.0

0.0

0.0

0.0

$-$

0.0

$6 e^{-10}$

0.0

$-$

$1 e^{-89}$

$1 e^{-178}$

0.0

0.0

$7 e^{-106}$

$6 e^{-68}$

$5 e^{-162}$

$-$

$2 e^{-76}$

$8 e^{-28}$

$1 e^{-76}$

a The order is according to their position described in Figure 1.

together with the Rdr1-RNAi construct into 91/100-5, increased the number of hyphal clusters fivefold $\left(P=2.2 \mathrm{e}^{-16}\right)$ compared to the GUS-control (Figures 4 and 5B). Furthermore, these clusters most closely resembled those of fully compatible interactions. The numbers of hyphal clusters were comparable to those found in experiments performed with the susceptible genotype Pariser 


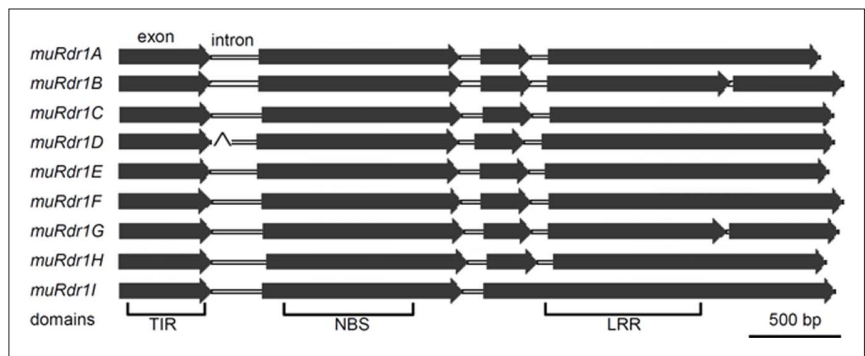

FIGURE 2 |The structure of the nineTNLs. The majority of the TNLs are characterized by four exons and three introns. The fourth TNL (muRdr1D) was interrupted by a 6957-bp transposable-element at intron 1.

Table 2 | Nucleotide and amino acid sequence similarity of the nine muRdr1-TNLs ${ }^{\mathrm{b}}$.

\begin{tabular}{llllllllll}
\hline & $\boldsymbol{A}$ & $\boldsymbol{B}$ & $\boldsymbol{C}$ & $\boldsymbol{D}$ & $\boldsymbol{E}$ & $\boldsymbol{F}$ & $\boldsymbol{G}$ & $\boldsymbol{H}$ & $\boldsymbol{I}$ \\
\hline muRdr1A & & 88.7 & 89.9 & 89.1 & 89.4 & 88.7 & 88.8 & 90.1 & 89.2 \\
muRdr1B & 78.6 & & 89.7 & 89.0 & 89.7 & 87.9 & $\mathbf{9 9 . 5}$ & 90.3 & 91.2 \\
muRdr1C & 80.4 & 79.3 & & 89.8 & 91.1 & 89.7 & 89.7 & 90.7 & 88.9 \\
muRdr1D & 79.5 & 80.6 & 80.0 & $\mathbf{1}$ & 92.9 & 88.3 & 89.2 & 91.8 & 88.6 \\
muRdr1E & 80.5 & 80.8 & 83.2 & 86.3 & & 88.7 & 89.7 & 93.8 & 88.6 \\
muRdr1F & 78.5 & 78.2 & 79.2 & 78.5 & 79.3 & & $\mathbf{8 7 . 8}$ & 89.5 & 87.9 \\
muRdr1G & 78.6 & $\mathbf{9 9 . 0}$ & 79.1 & 80.7 & 80.6 & $\mathbf{7 8 . 0}$ & & 90.6 & 91.3 \\
muRdr1H & 80.6 & 82.4 & 82.3 & 85.4 & 89.0 & 79.9 & 82.6 & & 88.8 \\
muRdr1I & 80.2 & 88.1 & 79.4 & 79.4 & 80.9 & 81.3 & 88.0 & 80.5 & \\
\hline
\end{tabular}

${ }^{b}$ Nucleotide sequence comparisons are shown above the diagonal and amino acid sequence comparisons are shown below the diagonal gray shaded marker. Numbers shown in bold print highlight minimum and maximum values.

Charme infiltrated with only conidia or conidia in combination with the GUS-construct in the same experiment (Figure 4). To our surprise, the infiltration of the Rdr1-RNAi construct together with conidia of DortE4 into the highly susceptible genotype Pariser Charme more than doubled the number of hyphal clusters compared to the GUS-intron control plasmid $\left(P=2.4 \mathrm{e}^{-5}\right)$, indicating a significant increase in susceptibility (Figure 4).

\section{ONE OF THE muRdr1 TNL GENES PARTIALLY COMPLEMENTS A SUSCEPTIBLE GENOTYPE IN A TRANSIENT ASSAY}

To identify the active resistance gene among the $m u R d r 1$ family members, we performed several transient infiltration experiments to test for complementation of susceptibility to DortE4 by individual $m u R d r 1$ TNLs. To accomplish this, we subcloned each of the genes except muRdr1D into the pBIN + binary plant transformation vector. In addition to the putative coding region, more than $3 \mathrm{~kb}$ of genomic DNA upstream of the putative ATG and more than $900 \mathrm{bp}$ downstream of the putative stop codon were included in the subclones to allow expression under the native promoters. The muRdr1D is interrupted by 6957-bp transposable-element insertion within intron 1 . As a result, we speculated $m u R d r 1 D$ as nonfunctional and excluded from subcloning and functional analysis.

All eight muRdr1 TNLs were transformed into Agrobacterium strain GV 3101 and transiently expressed in leaves of Nicotiana benthamiana (Wroblewski et al., 2005; Yasmin and Debener, 2010).
Expression was analyzed by RT-PCR on cDNA generated from infiltrated leaf areas with PCR primer pairs from the first and last exons. The cDNA from leaves infiltrated with GUS controls did not produce a PCR signal. In contrast to the expression analyses in roses, all eight subclones produced PCR fragments with sizes as expected for expressed sequences (data not shown). Because no tobacco ortholog with sufficient similarity could be detected, this indicates heterologous expression of all eight $m u R d r 1$ genes tested.

Leaves of the susceptible rose genotype Pariser Charme were infiltrated with only conidia or conidia and Agrobacteria carrying control plasmid; the conidia germinated and formed dense clusters of hyphae after 4 days (Figure 5C). In nine independent experiments, conidia of the race six isolate DortE4 were co-infiltrated at low densities $\left(5 \times 10^{2}\right.$ conidia per $\left.\mathrm{ml}\right)$ into the susceptible rose genotype Pariser Charme with Agrobacteria harboring different muRdr1 TNLs (Figure 6). Conidial germination and hyphal clusters occurred in all experiments including $m u R d r 1$ genes and no significant differences in the morphology of the hyphal clusters could be observed between treatments. However, in all nine experiments, $m u R d r 1 H$ led to a significant reduction of the number of hyphal clusters compared to the controls and the other $m u R d r 1$ TNL genes. On average, the number of hyphal clusters was reduced to $54 \%$ of the number of hyphal clusters present in the control experiments (Figure 6).

\section{THE EFFECT OF muRdr1H IS SPECIFIC FOR THE INTERACTION WITH RACE 6 ISOLATES OF BLACK SPOT}

The same experimental strategy was applied using the race 7 isolate R6, which is able to infect genotypes carrying the $R d r 1$ resistance gene (Whitaker et al., 2010b). In three independent experiments, $m u R d r 1 H$ had no effect on the infection process compared to the control plasmid (Figure 7), indicating that the effect of $m u R d r 1 H$ on the growth of isolate DortE4 is specific for this pathogen.

\section{DISCUSSION}

In this study we show that the black spot resistance gene $R d r 1$ is a member of a highly conserved family of TNL (TIR-NBS-LRR) resistance genes.

The copy number of resistance gene paralogs may vary between species. Copy numbers of Hcr9 ranging from one to five were observed in tomato (Parniske and Jones, 1999); 12-32 copies of $R G C 2$ were estimated in lettuce (Kuang et al., 2004); 8-10 copies of RPP5 were found in Arabidopsis (Noël et al., 1999) and four Vf paralogs were detected in apple (Xu and Korban, 2002). The nine $m u R d r 1$ paralogs obtained from $R$. multiflora are within the range already shown for other plant species. The observed variation in copy number may be a result of a birth-and-death model of resistance gene evolution as reviewed in Michelmore and Meyers (1998), with this model being suspected to occur for lettuce RGC2 (Kuang et al., 2004).

The muRdrl genomic sequence size varied from 4085 bp to $5920 \mathrm{bp}$. This observation is within the size range of previously reported NBS-LRR genes; for example, resistance gene analog (RGA) 1 and RGA2 genes in wheat had lengths of 3905 and 4766 bp, respectively (Wicker et al., 2001). The hypothesis that $m u R d r 1$ is a hotspot for resistance genes is supported by the fact 


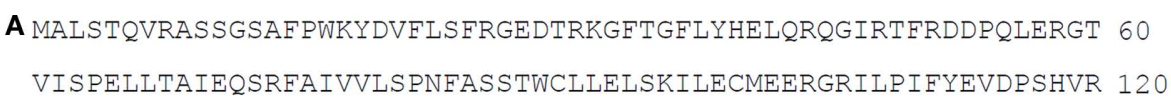
HQRGSFAEAFQEHEEKFGVGNKKVEGWRDALTKVAGLAGWTSKDYRYETELIREIVQALW 180

SKLHPSLTVFGSSEKLFGMDSKLEEIDVLLDKEANEVRFIGIWGMGGIGKTTLARLVYQK 240
hhGREXE ISHQFEVCIFLDNVREVSKTTHGLVDLQKKILSQI FKEENVQVLDVYSGMTMIKRCVCNK 300 RNBS-A

AVLLVLDDMDQSEQLENLVGEKDCFGLRSRIIITTRDRHVLVTHGVEKPYELNGLNKNEA 360

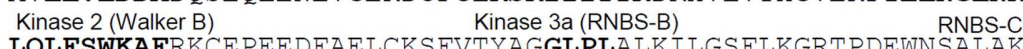
LQLFSWKAFRKCE PEEDFAELCKS FVTYAGGLPLALKILGSFLKGRTPDEWNSALAKLQQ 420

GLPL
RPDSS-C
TPDITFKILKMSFDGLDEMEKKIFLDIACFRWLYRKEFMIELVDSSDPCNRITRSVLAE 480

GLPL
RPDSS-C
TPDITFKILKMSFDGLDEMEKKIFLDIACFRWLYRKEFMIELVDSSDPCNRITRSVLAE 480 RNBS-D

KSLLTISSDNQVHVHDLIHEMGCEIVRQENKE PGGRSRLCLRDDI FHVFTKNTGTEAIEG 540

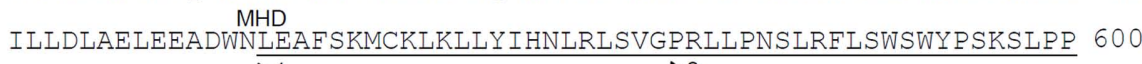
$\begin{array}{ll}\text { CFQPDELAEISLVHSNIDHLWNGIKYLVNLKSIDLSYSINLTRTPDFTGIPNLEKLVLEG } & 660\end{array}$

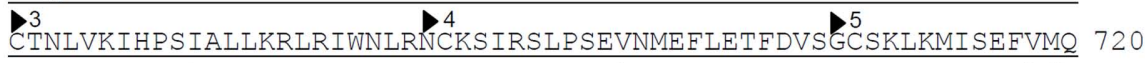
MKRLSKLYLGGTAVEKLPSSIEHLSESLVVLDLSEIVIREQPYSRLLKQNLIASSFGLFP 780 RKSPHPLIPLLASLKHFSCLRTLKLNDCNLCEGEIPNDIGSLSSLQRLELRGNNFVSLPA 840 SIHLLEDVDVENCKRLQQLPELPDLPNLCRLRANFWLNCINCLSMVGNQDASYFLYSVLK 900 RWIEIEALSRCDMMIRQETHCSFEYFRFVIPGSEIPEWFNNQSVGDTVTEKLPWDACNSK 960

WIGFAVCALIVPHDNPSAVPEKSHLDPDTCCIWCFWNDYGIDVIGVGTNNVKQIVSDHLY 1020

LLVLPSPERKPENYLEVNFVFKIARAVGSNRGMKVKKCGVRALYEHDTEELISKMNQSKT 1080

SSISLYEEAMDEQEGAMVKATQEAATSRSGGSDDEYYSAAEE

B
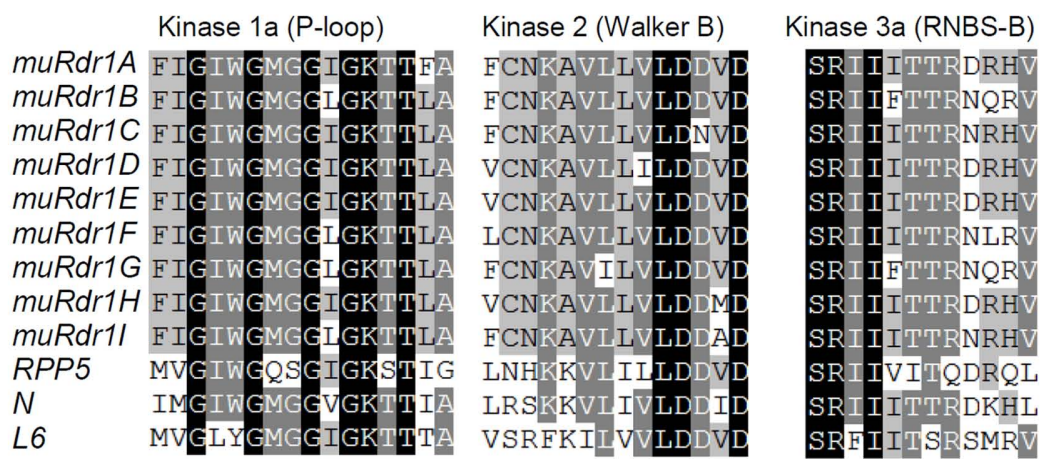

FIGURE 3 |The muRdr1 protein sequence and conserved motifs. (A) muRdr1H protein sequence. Conserved motifs are indicated as bold letters and the 14 imperfect leucine-rich repeats (LRRs) are underlined. (B) Alignments of kinase motifs in the conserved region for the nine TNLs and three previously described resistance genes, RPP5 (Arabidopsis, accession number: AAF08790), N (tobacco, accession number: AAA50763), and L6 (flax, accession number: AAA91022). that repetitive transposable-elements, similar to the unusually large repetitive transposable-elements distributed in the $m u R d r 1$ region, are reported along resistance genes in wheat (Wicker et al., 2001), in potato (Kuang et al., 2005), in tomato (Parniske and Jones, 1999), in Arabidopsis (Noël et al., 1999), in maize (Sun et al., 2001), in rice (Song et al., 1997), and in lettuce (Meyers et al., 1998).

$R d r 1$ is the first disease-resistance gene isolated from roses and also the first gene isolated from roses via positional cloning. These advances were possible because our transient expression assay allowed us to assay a large number of candidate genes within a relatively short period of time.

Although roses have some characteristics that make them an ideal model for woody perennials, such as a generation time of less than a year and a relatively small genome size of around $500 \mathrm{Mb}$
(Debener and Linde, 2009), genetic complementation experiments are very difficult due to low transformation rates and a lengthy transformation process (Dohm, 2003). Therefore, the transient assay that we employed in this study offers an alternative to stable transformation experiments in that it is much faster (a single experiment takes around 1 week) and circumvents problems in the analyses of single transgenic plants, such as positional and copy number effects. Furthermore, this assay makes possible the characterization of a large number of candidate genes that would be impossible to screen via stable transformation at transformation rates of around 3\% (Dohm et al., 2002).

The susceptibility of leaf areas infiltrated with the $m u R d r 1 H$ gene was reduced to $54 \%$ compared to control infiltrations. However, in all of the nine biological replicates, a pair-wise comparison between areas 
infiltrated with $m u R d r 1 H$ and those infiltrated with a control plasmid revealed a statistically significant reduction of mycelia colonies formed after co-infiltration of fungal conidia and Agrobacteria. This partial reduction of infection is most probably caused by the much lower efficiency of transient transformation of rose leaf cells compared to results obtained with N. benthamiana (Yasmin and Debener, 2010). Furthermore, we expressed the $R d r 1$ candidate genes under their

Table 3 | Expression profiles of single muRdr1TNLs in a homologous system.

\begin{tabular}{|c|c|c|c|c|}
\hline \multirow[t]{2}{*}{ TNLs } & \multicolumn{2}{|c|}{$\begin{array}{l}\text { Rose genotype- } \\
\text { 88/124-46 }\end{array}$} & \multicolumn{2}{|c|}{$\begin{array}{c}\text { Rose genotype-91/ } \\
100-5\end{array}$} \\
\hline & Leaves* & Petals & Leaves & Petals \\
\hline muRdr1A & + & + & + & + \\
\hline muRdr1B & + & - & - & - \\
\hline muRdr1C & + & + & + & + \\
\hline muRdr1D & - & - & - & - \\
\hline muRdr1E & - & - & - & - \\
\hline muRdr1F & - & - & - & - \\
\hline muRdr1G & + & + & + & + \\
\hline muRdr1H & + & + & + & + \\
\hline muRdr1I & + & + & + & + \\
\hline
\end{tabular}

${ }^{*}+$ = expressed $;-=$ not detectable. natural promoters, which induce very low levels of expression in the natural context, comparable to the majority of the NB-LRR coding genes characterized so far (for example: Wroblewski et al., 2007). The reduction of infection observed in our assays with the functional $R d r 1$ gene is comparable to the reduction of infection as observed in the transient leaf assays employed to analyze dominant resistance genes in cereals (Yahiaoui et al., 2004; Douchkov et al., 2005; Keller et al., 2005). In these assays, the function of resistance gene candidates was tested in transient assays of particle-bombarded epidermal cells. Here, the function of a candidate gene is determined by a statistically significant reduction in the number of epidermal cells with developed haustoria as observed in inoculated transgenic cells.

The transient silencing of the muRdr1 TNL-family gene revealed loss of resistance in the naturally resistant plant. This is an indication that the resistance gene $R d r 1$ is indeed the TNL type resistance gene as reported in the majority of other plant species (Sanseverino et al., 2009). The complementation analysis using the individual muRdr1 TNL-construct further confined the Rdr1 gene to the muRdr1H. Sequence analysis of the muRdr1H indicated conservation of protein motifs typical for plant resistance genes (Traut, 1994; Hammond-Kosack and Jones, 1997; van Ooijen et al., 2008). We started cloning muRdr $1 \mathrm{H}$ homologs from several susceptible rose species including the parent of the cross which led to the identification of the $R d r 1$ locus. Preliminary sequence analysis revealed clear polymorphisms along the complete gene regions with a maximum amino acid sequence similarity of $87 \%$ (data not shown). Therefore,

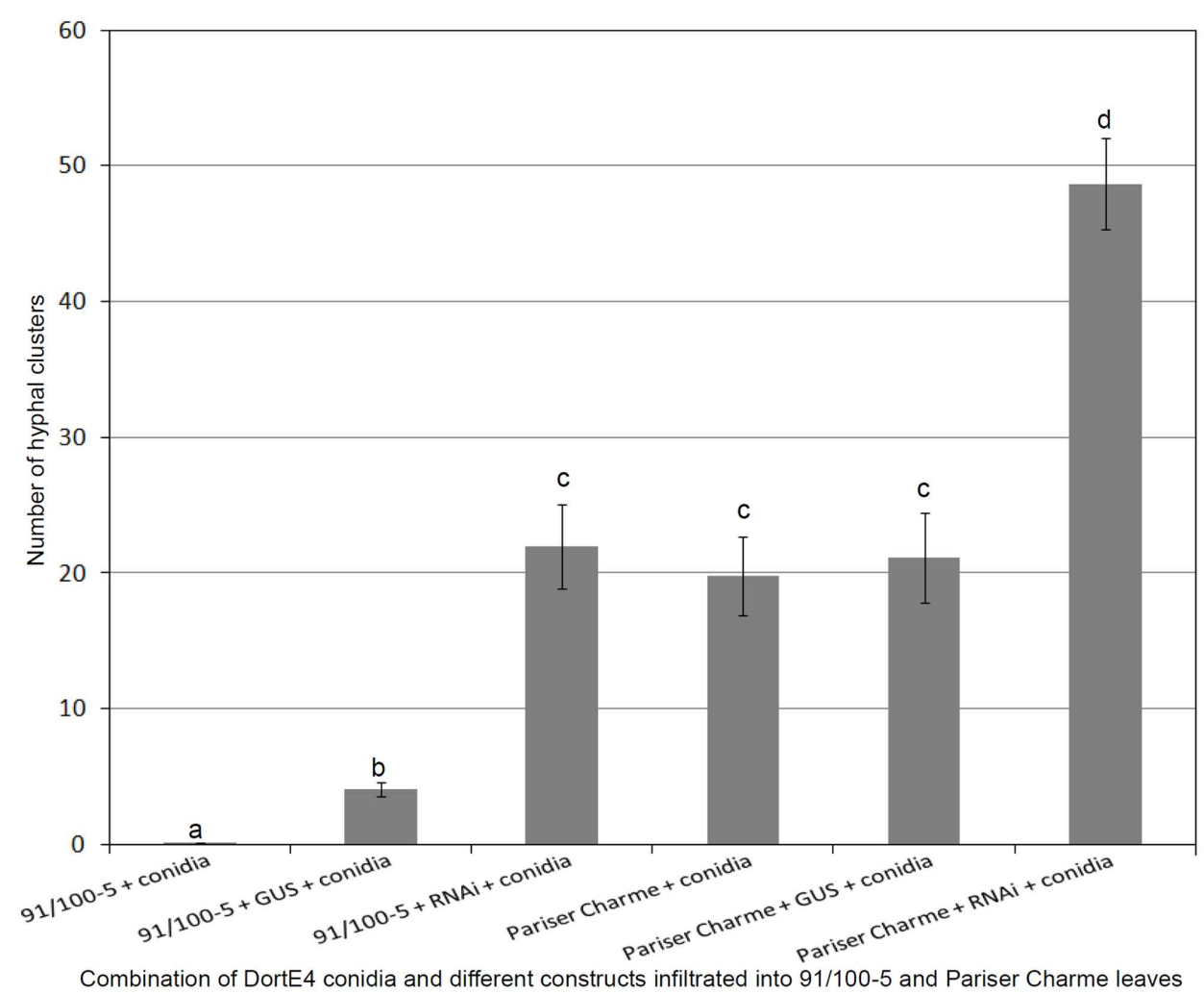

FIGURE 4 | Results of the transient silencing experiment in genotype 91/100-5 and Pariser Charme rose leaves. Values are averages for 20 replications each \pm SEM. The number of hyphal clusters are significantly increased in 91/100-5 leaves carrying Rdr 1-RNAi construct. Results with same letters are not significantly different $(P<0.05)$ 

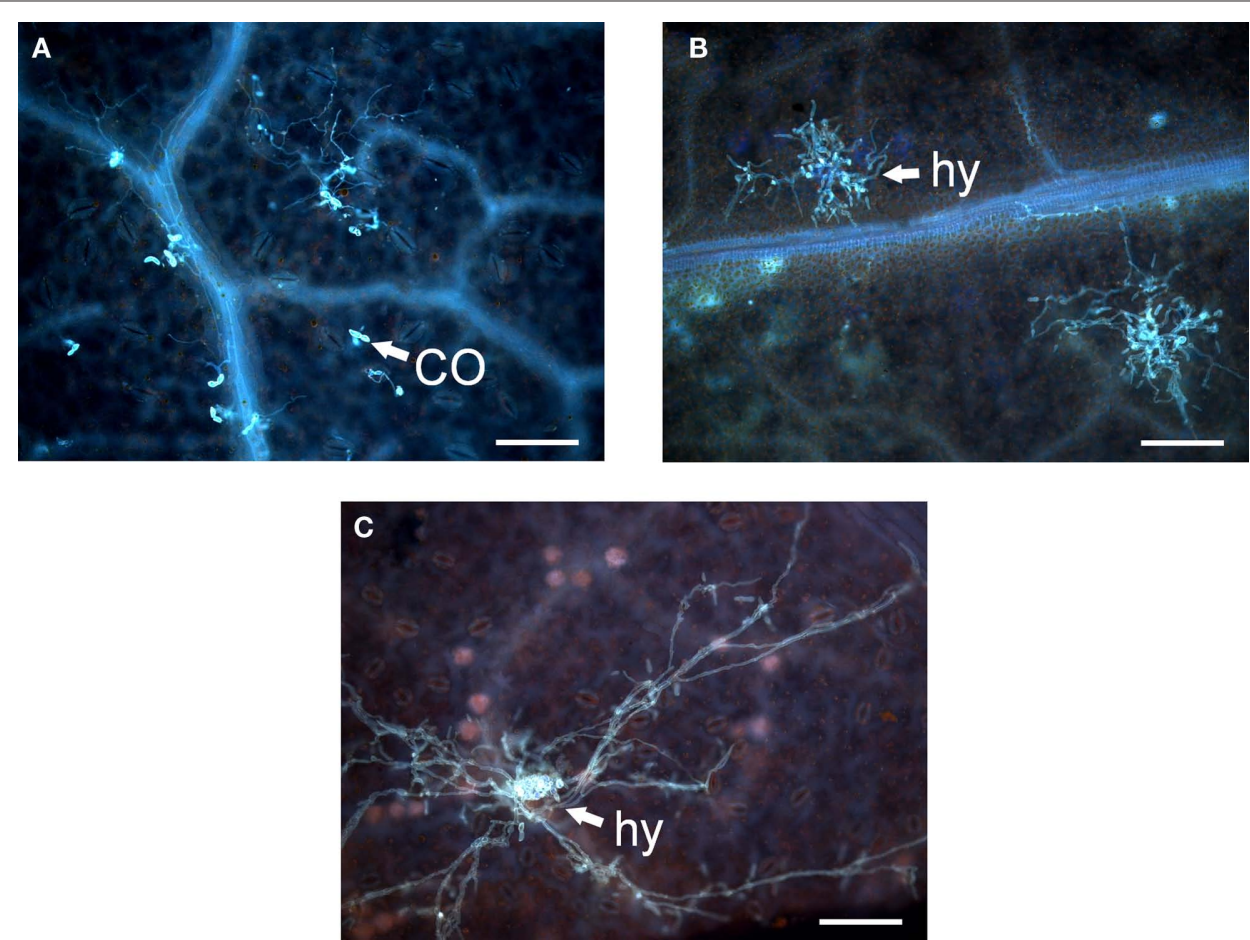

FIGURE 5 | Infiltration of rose leaves with black spot conidia or black spot conidia and Agrobacteria containing various constructs. (A) Resistant genotype 91/100-5 infiltrated with conidia (CO) of Dort E4 and Agrobacterium strain GV3101 harboring pBIN19::GUS-intron. (B) Infiltration of 91/100-5 with conidia of Dort E4 and Agrobacterium strain GV3101 harboring Rdr1-RNAi displaying a compatible interaction. (C) Infiltration of Pariser Charme with conidia of Dort E4 displaying a compatible interaction with a hyphal cluster (hy) and young acervulus in the middle. The scale bar indicates $100 \mu \mathrm{m}$.

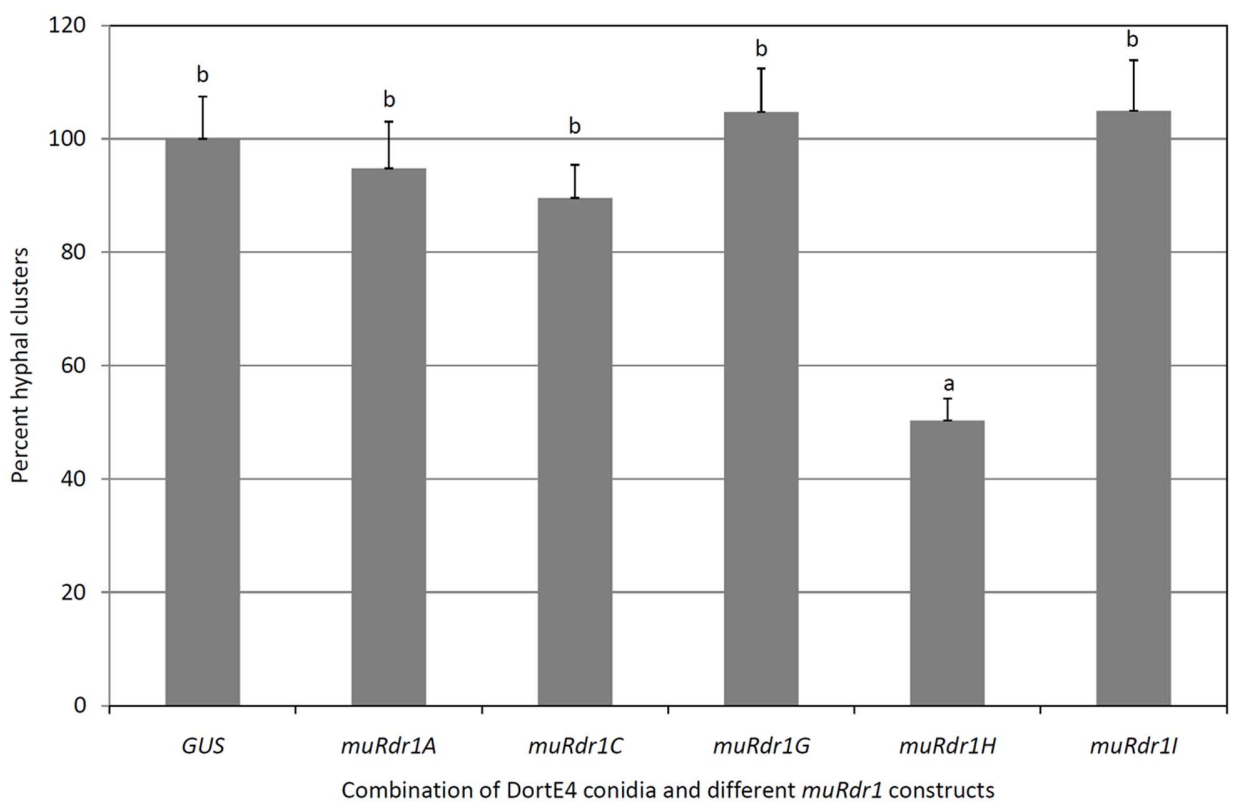

FIGURE 6 | Transient complementation disease assay with individual muRdr1 TNLs and DortE4. This graph represents average data of nine independent experiments \pm SEM. Highly significant reduction in the percent hyphal cluster is observed in Pariser Charme rose plants infiltrated with muRdr $1 \mathrm{H}$ than the otherTNLs. Results with same letters are not significantly different $(P<0.05)$. 


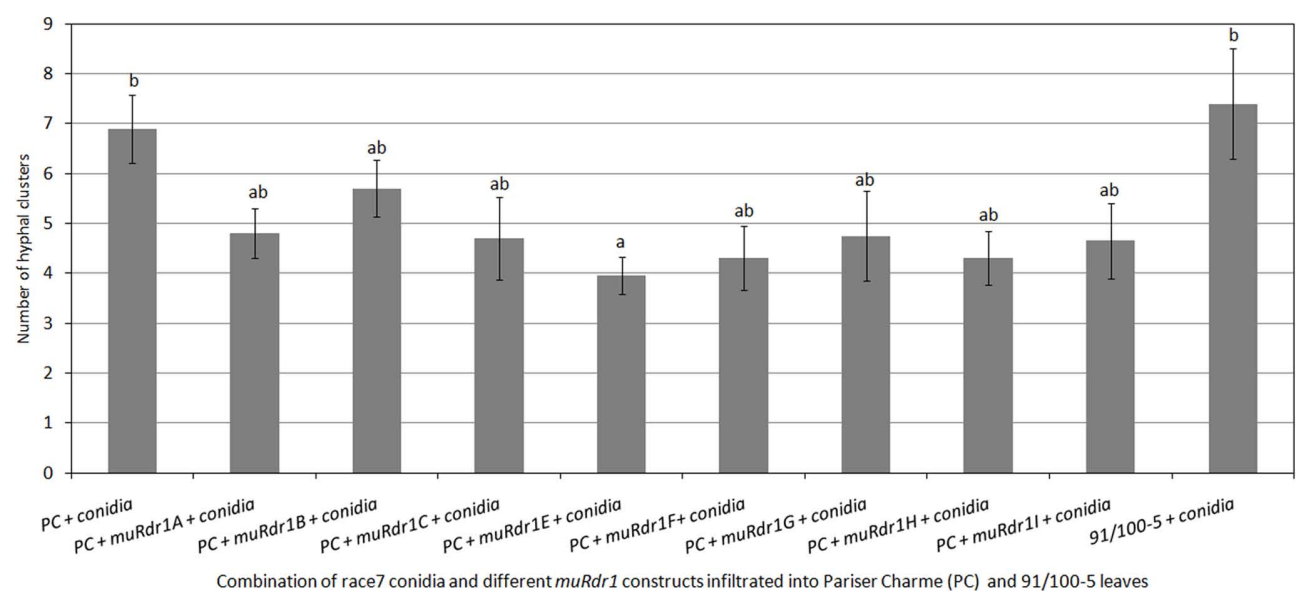

FIGURE 7 | Transient complementation disease assay with individual muRdr1TNLs and race7. This graph represents average data of three independent experiments \pm SEM. No significant difference in the number of hyphal clusters is observed between the eight muRdr1TNLs. There is also no significant difference between muRdr1H infiltrated rose cultivar and the non-infiltrated. Results with same letters are not significantly different $(P<0.05)$. a single mutation explaining the difference between the susceptible and the resistant genotype cannot be identified among the numerous differences. More extensive analyses will be done in the future, which may lead to a detection of functional mutation responsible for the loss of resistance in the susceptible rose species.

The identification of $R d r 1$ and the analyses of expression of the family members were complicated by the highly duplicated nature of the $R d r 1$ gene family and a high degree of conservation among the individual members. In several independent experiments, we found five members of the $m u R d r 1$ family expressed in leaves and petals, whereas all members were expressed in tobacco leaves. The most likely reason for this is a specific down regulation of individual family members in roses by either regulatory elements missing in our genomic clones or other mechanism such as siRNA, a phenomenon already described for a cluster of $R$ genes in Arabidopsis (Yi and Richards, 2007). However, further experimental evidence is necessary to analyze these observations.

Most plant $R$ genes exist in clusters (Hulbert et al., 2001). The different $R$ gene paralogs in the same cluster may confer resistance to multiple pathogens or distinct isolates of a single pathogen (van der Vossen et al., 2000). Because five of the nine Rdr1 paralogs from R. multiflora are expressed in leaves and flowers, we may also be able to identify additional $R$ genes within the $m u R d r 1$ cluster with transient assays involving additional fungal isolates. In a recent update on the number of physiological races of the black spot fungus, a minimum of 11 races was characterized (Whitaker et al., 2010b). In

\section{REFERENCES}

Altschul, S. F., Madden, T. L., Schaffer, A. A., Zhang, J., Zhang, Z., Miller, W., and Lipman, D. J. (1997). Gapped BLAST and PSI-BLAST: a new generation of protein database search programs. Nucleic Acids Res. 25, 3389-3402.

Biber, A., Kaufmann, H., Linde, M., Spiller, M., Terefe, D., and Debener, T. (2010). Molecular markers from a BAC contig spanning the Rdr1 locus: a tool for marker-assisted selection in roses. Theor. Appl. Genet. 120, 765-773.
Debener, T., Drevez-Alvarez, R., and Rockstroh, K. (1998). Identification of five physiological races of black spot, Diplocarpon rosae Wolf, on roses. Plant Breed. 117, 267-270.

Debener, T., and Linde, M. (2009). Exploring complex ornamental genomes: the rose as a model plant. CRC Crit. Rev. Plant Sci. 28, 267-280.

Dodds, P. N., and Rathjen, J. P. (2010). Plant immunity: towards an integrated view of plant-pathogen interactions. Nat. Rev. Genet. 11, 539-548.

addition, we previously identified rose germplasm resistant to several isolates of black spot as well as to various isolates of Peronospora sparsa, which causes downy mildew in roses, and Podosphaera pannosa, which causes powdery mildew on roses (Schulz et al., 2009; Whitaker et al., 2010b). Based on a screen of a number of diploid and tetraploid roses with an SSR marker located within the last exon (Terefe and Debener, 2010), and on the complete sequence of an orthologous contig from a genotype of $R$. rugosa (Terefe et al., 2010), we know that the $R d r 1$ gene family is comprised of between 5 and 20 members in different rose genomes. Because some of these genotypes are resistant to race five isolates, it is now possible to analyze the role of $R d r 1$ orthologs and paralogs in this and other interactions based on the transient assay. We now have a tool at hand with which we will be able to analyze the evolution of plant pathogen interactions in a non-model species with a combination of life history traits of both partners (long-lived woody perennial host and mostly asexually reproducing pathogen with moderate gene flow rates) that has, to date, not been studied.

\section{ACKNOWLEDGMENTS}

This study was supported by the German Research Foundation (DFG) grant number DE 511/4-1 and DE 511/4-2. Aneela Yasmin was supported by a scholarship from German Academic Exchange Service (DAAD). We thank Ingrid Robotta for excellent technical assistance. We also thank Maik Klie for assisting in the BACsubcloning and screening experiments.

Dohm, A. (2003). "Biotechnologies for breeding: genetic transformation," in Encyclopedia of Rose Sciences, eds A. V. Roberts, T. Debener, and S. Gudin (Oxford: Elsevier Academic Press), 15-25.

Dohm, A., Ludwig, C., Schilling, D., and Debener, T. (2001). Transformation of roses with genes for antifungal proteins. Acta Hortic. 547, 27-33.

Dohm, A., Ludwig, C., Schilling, D., and Debener, T. (2002). Transformation of roses with genes for antifungal proteins to reduce their susceptibility to fungal diseases. Acta Hortic. 572, 105-111.

Douchkov, D., Nowara, D., Zierold, U., and Schweizer, P. (2005). A high-throughput gene-silencing system for the functional assessment of defense-related genes in barley epidermal cells. Mol. Plant Microbe Interact. 18, 755-761.

Drewes-Alwarez, R. (2003). “Black spot,” in Encyclopedia of Rose Sciences, eds A. V. Roberts, T. Debener, and S. Gudin (Oxford: Elsevier Academic Press), 148-153. 
Eitas, T. K., and Dangl, J. L. (2010). NB-LRR proteins: pairs, pieces, perception, partners, and pathways. Curr. Opin. Plant Biol. 13, 472-477.

Finn, R. D., Tate, J., Mistry, J., Coggill, P. C., Sammut, J. S., Hotz, H. R., Ceric, G., Forslund, K., Eddy, S. R., Sonnhammer, E. L., and Bateman, A. (2008). The Pfam protein families database. Nucleic Acids Res. 36, D281-D288.

Gachomo, E. W., and Kotchoni, S. O. (2010). Microscopic and biochemical evidence of differentially virulent field isolates of Diplocarpon rosae causing black spot disease of roses. Plant Physiol. Biochem. 48, 167-175.

Hall, T.A. (1999). BioEdit: a user-friendly biological sequence alignment editor and analysis program for Windows 95/98/NT. Nucleic Acids Symp. Ser. 41, 95-98.

Hammond-Kosack, K. E., and Jones, J. D. G. (1997). Plant disease resistance genes. Annu. Rev. Plant Physiol. Plant Mol. Biol. 48, 575-607.

Hood, M. E., and Shew, H. D. (1996). Applications of $\mathrm{KOH}$ aniline blue fluorescence in the study of plantfungal interactions. Phytopathology 86, 704-708.

Horst, R. K. (2008). Westcott's Plant Disease Handbook, 7th Edn. Dordrecht: Springer Science.

Hulbert, S. C., Webb, C. A, Smith, S. M., and Sun, Q. (2001). Resistance gene complexes: evolution and utilization. Annu. Rev. Phytopathol. 39, 285-312.

Kaufmann, H., Mattiesch, L., Lorz, H., and Debener, T. (2003). Construction of a BAC library of Rosa rugosa Thunb. and assembly of a contig spanning Rdr1, a gene that confers resistance to black spot. Mol. Genet. Genomics 268, 666-674.

Keller, B., Feuillet, C., and Yahiaoui, N. (2005). Map-based isolation of disease resistance genes from bread wheat: cloning in a supersize genome. Genet. Res. 85, 93-100.

Kuang, H., Wei, F., Marano, M. R., Wirtz, U., Wang, Z., Liu, J., Shum, W. P., Zaborsky, J., Tallon, L. J., Rensink, W., Lobst, S., Zhang, P., Tornqvist, C. E., Tek, A., Bamberg, J., Helgeson, J., Fry, W., You, F., Luo, M. C., Jiang, J., Buell, C. R., and Baker, B. (2005). The R1 resistance gene cluster contains three groups of independently evolving, type I R1 homologues and shows substantial structural variation among haplotypes of Solanum demissum. Plant J. 44, 37-51.

Kuang, H., Woo, S. S., Meyers, B. C., Nevo, E., and Michelmore, R. W. (2004). Multiple genetic processes result in heterogeneous rates of evolution within the major cluster disease resistance genes in lettuce. Plant Cell 16, 2870-2894
Letunic, I., Doerks, T., and Bork, P. (2009). SMART 6: recent updates and new developments. Nucleic Acids Res. 37, D229-D232.

Lühmann, A. K., Linde, M., and Debener, T. (2010). Genetic diversity of Diplocarpon rosae: implications on practical breeding. Acta Hortic. 870, 157-162.

Marchler-Bauer, A., Anderson, J. B., Derbyshire, M. K., DeWeese-Scott, C., Gonzales, N. R., Gwadz, M., Hao, L., He, S., Hurwitz, D. I., Jackson, J. D., Ke, Z., Krylov, D., Lanczycki, C. J., Liebert, C. A., Liu, C., Lu, F., Lu, S., Marchler, G. H., Mullokandov, M., Song, J. S., Thanki, N., Yamashita, R. A., Yin, J. J., Zhang, D., and Bryant, S. H. (2007). CDD: a conserved domain database for interactive domain family analysis. Nucleic Acids Res. 35, D237-D240.

McHale, L., Tan, X. P., Koehl, P., and Michelmore, R. W. (2006). Plant NBS-LRR proteins: adaptable guards. Genome Biol. 7, 212.

Meyers, B. C., Chin, D. B., Shen, K. A., Sivaramakrishnan, S., Lavelle, D. O., Zhang,Z., and Michelmore, R.W.(1998). The major resistance gene cluster in lettuce is highly duplicated and spans several megabases. Plant Cell 10, 1817-1832.

Michelmore, R. W., and Meyers, B. C. (1998). Clusters of resistance genes in plants evolve by divergent selection and a birth-and death process. Genome Res. 8, 1113-1130.

Noël, L., Moores, T. L., van der Biezen, E. A., Parniske, M., Daniels, M. J., Parker, J. E., and Jones, J. D. G. (1999). Pronounced intraspecific haplotype divergence at the RPP5 complex disease resistance locus of Arabidopsis. Plant Cell 11, 2099-2111.

Parniske, M., and Jones, J. D. G. (1999). Recombination between diverged clusters of the tomato Cf-9 plant disease resistance gene family. Proc. Natl. Acad. Sci. U.S.A. 96, 5850-5855.

R Development Core Team. (2009). R: A Language and Environment for Statistical Computing. Vienna: R Foundation for Statistical Computing. Sambrook, J., and Russell, D. W. (2001). Molecular Cloning: A Laboratory Manual, 3rd Edn. Cold Spring Harbor: Cold Spring Harbor Laboratory Press.

Sanseverino, W., Roma, G., De Simone, M., Faino, L., Melito, S., Stupka, E., Frusciante, L., and Ercolano, M. R. (2009). PRGdb: a bioinformatics platform for plant resistance gene analysis. Nucleic Acids Res. 38, D814-D821.

Schulz, D. F., Linde, M., Blechert, O., and Debener, T. (2009). Evaluation of genus Rosa germplasm for resistance to black spot, downy mildew and powdery mildew. Eur. J. Hortic. Sci. 74, 1-9.

Seo, Y. S., Rojas, M. R., Lee, J. Y., Lee, S. W., Jeon, J. S., Ronald, P., Lucas, W. J., and Gilbertson, R. L. (2006). A viral resistancegene from common bean functions across plant families and is upregulated in a non-virus-specific manner. Proc Natl. Acad. Sci. U.S.A. 103, 11856-11861.

Song, W. Y., Pi, L. Y., Wang, G. L., Gardner, J., Holsten, T., and Ronald, P. C. (1997). Evolution of the rice Xa21 disease resistancegenefamily. Plant Cell 9, 1279-1287.

Sun, Q., Collins, N. C., Ayliffe, M., Smith, S. M., Drake, J., Pryor, T., and Hulbert, S. H. (2001). Recombination between paralogues at the rp1 rust resistance locus in maize. Genetics 158, 423-438.

Terefe, D., Biber, A., Yasmin, A. Kaufmann, H., and Debener, T. (2010). Comparative genomic analysis of sequences around the Rdr1 locus in resistant and susceptible rose genotypes. Acta Hortic. 870, 197-204.

Terefe, D., and Debener, T. (2010). An SSR from the LRR region of the rose Rdr1 gene family is a useful RGA marker for roses and other Rosaceae. Plant Breed. 130, 291-293.

Traut, T. W. (1994). The functions and consensus motifs of nine types of peptide segments that form different types of nucleotide-binding sites. Eur. J. Biochem. 222, 9-19.

van der Vossen, E. A., Van der Voort, J. N., Kanyuka, K., Bendahmane, A., Sandbrink, H., Baulcombe, D. C., Bakker, J., Stiekema, W. J., and KleinLankhorst, R. M. (2000). Homologues of a single resistance-gene cluster in potato confer resistance to distinct pathogens: a virus and a nematode. Plant J. 23, 567-576.

van Engelen, F. A., Molthoff, J.W., Conner, A. J., Nap, J.P., Pereira, A., and Stiekema, W. J. (1995). pBINPLUS: an improved plant transformation vector based on pBIN19. Transgenic Res. 4, 288-290.

van Ooijen, G., Mayr, G., Kasiem, M. M. A., Albrecht, M., Cornelissen, B. J. C., and Takken, F. L.W. (2008). Structurefunction analysis of the NB-ARC domain of plant disease resistance proteins. J. Exp. Bot. 59, 1383-1397.

Whitaker, V. M., Bradeen, J. M., Debener, T., Biber, A., and Hokanson, S. C. (2010a). Rdr3, a novel locus conferring black spot disease resistance in tetraploid rose: genetic analysis, LRR profiling, and SCAR marker development. Theor. Appl. Genet. 120, 573-585.

Whitaker, V. M., Debener, T., Roberts, A. V., and Hokanson, S. C. (2010b). A standard set of host differentials and unified nomenclature for an international collection of Diplocarpon rosae races. Plant Pathol. 59, 745-752.

Whitham, S., Dineshkumar, S. P., Choi, D., Hehl, R., Corr, C., and Baker, B. (1994). The product of the tobacco mosaic virus resistance gene $\mathrm{N}$-similarity to Toll and the interleukin-1 receptor. Cell 78, 1101-1115.

Wicker, T., Stein, N., Albar, L., Feuillet, C., Schlagenhauf, E., and Keller, B. (2001) Analysis of a contiguous $211 \mathrm{~kb}$ sequence in diploid wheat (Triticum monococcum L.) reveals multiple mechanisms of genome evolution. Plant J. 26, 307-316.

Wroblewski, T., Piskurewicz, U., Tomczak, A., Ochoa, O., and Michelmore, R. W. (2007). Silencing of the major family of NBS-LRR-encoding genes in lettuce results in the loss of multiple resistance specificities. Plant J. 51, 803-818.

Wroblewski, T., Tomczak, A., and Michelmore, R. (2005). Optimization of Agrobacterium-mediated transient assays of gene expression in lettuce, tomato and Arabidopsis. Plant Biotechnol. J. 3, 259-273.

$\mathrm{Xu}, \mathrm{M}$., and Korban, S. S. (2002). A cluster of four receptor-like genes resides in the Vf locus that confers resistance to apple scab disease. Genetics 162, 1995-2006.

Yahiaoui, N., Srichumpa, P., Dudler, R. and Keller, B. (2004). Genome analysis at different ploidy levels allows cloning of the powdery mildew resistance gene $\mathrm{Pm} 3 \mathrm{~b}$ from hexaploid wheat. Plant $J$. 37, 528-538.

Yang, S., Zhang, X., Yue, J.X., Tian, D., and Chen,J.Q. (2008). Recent duplications dominate NBS-encoding gene expansion in two woody species. Mol. Genet. Genomics 280, 187-198.

Yasmin, A., and Debener, T. (2010) Transient gene expression in rose petals via Agrobacterium infiltration. Plant Cell Tissue Organ Cult. 102, 245-250.

Yi, H., and Richards, E. J. (2007). A cluster of disease resistance genes in Arabidopsis is co-ordinately regulated by transcriptional activation and RNA silencing. Plant Cell 19, 2929-2939.

Conflict of Interest Statement: The authors declare that the research was conducted in the absence of any commercial or financial relationships that could be construed as a potential conflict of interest.

Received: 17 June 2011; accepted: 18 July 2011; published online: 01 August 2011.

Citation: Terefe-Ayana D, Yasmin A, Le TL, Kaufmann H, Biber A, Kühr A, Linde $M$ and Debener T (2011) Mining diseaseresistance genes in roses: functional and molecular characterization of the Rdr1 locus. Front. Plant Sci. 2:35. doi: 10.3389/ fpls.2011.00035

This article was submitted to Frontiers in Crop Science and Horticulture, a specialty of Frontiers in Plant Science.

Copyright (๑) 2011 Terefe-Ayana, Yasmin, Le, Kaufmann, Biber, Kühr, Linde and Debener. This is an open-access article subject to a non-exclusive license between the authors and Frontiers Media SA, which permits use, distribution and reproduction in other forums, provided the original authors and source are credited and other Frontiers conditions are complied with. 


\section{APPENDIX}

Table A1 | List of primers utilized for expression analysis of TNL genes.

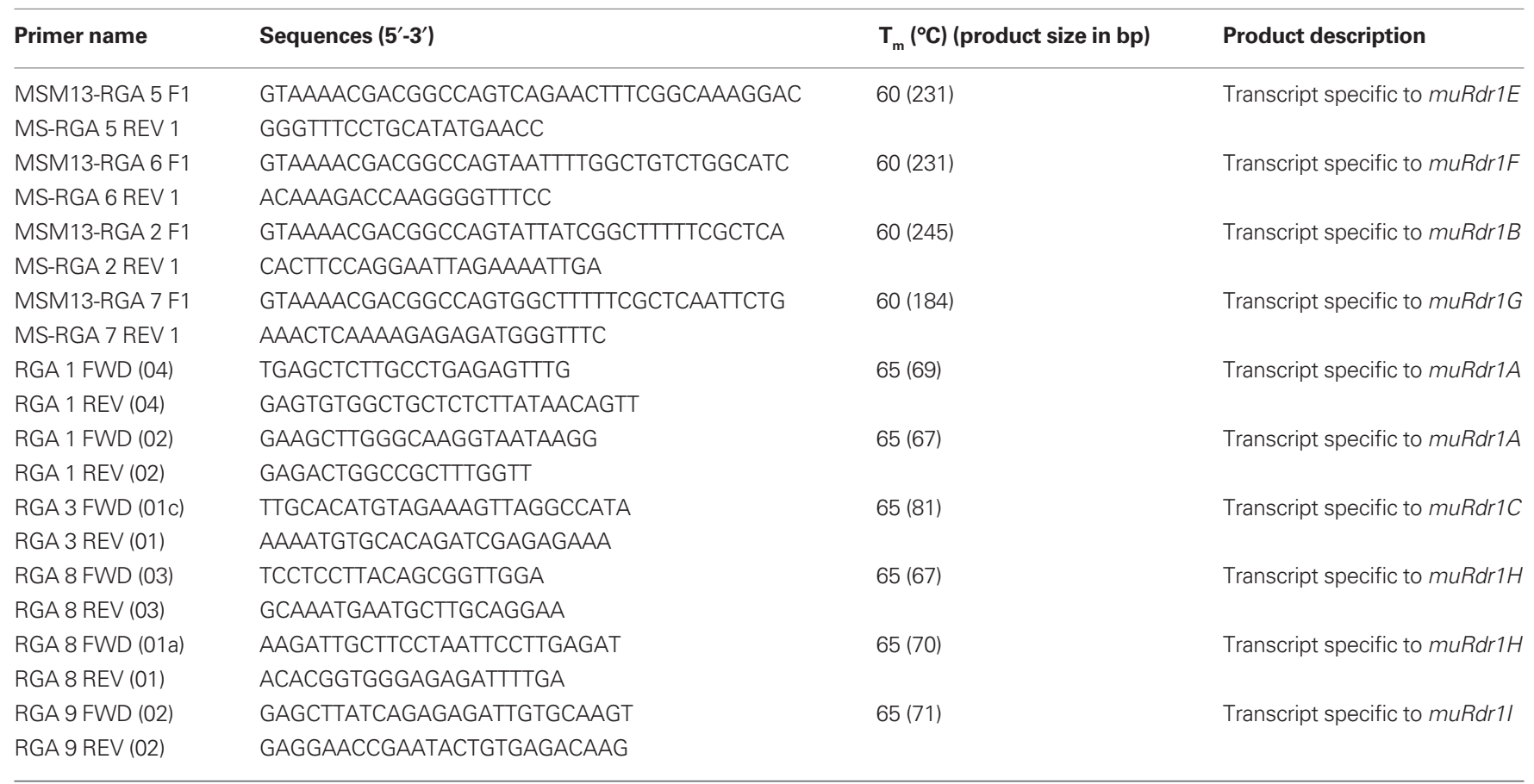

Table A2 | List of primers utilized for selection and analysis of BAC-subclones and TNL genes.

\begin{tabular}{|c|c|c|c|}
\hline Primer name & Sequences $\left(5^{\prime}-3^{\prime}\right)$ & $T_{m}\left({ }^{\circ} \mathrm{C}\right)$ (product size in bp) & Product description \\
\hline Actin-F & CGAGGAAGATCTGGCATCA & $60(600)$ & Internal control for RT-PCR \\
\hline Actin-R & AGGAGCTGCTCTTGGCAGT & & \\
\hline consP1-B & TCСACTCAAATCAAGCTCCA & & the nine muRdr1 family \\
\hline M13-F & GTAAAACGACGGCCAGT & 52 (variable) & Identify BAC-subclones carrying any positive constructs \\
\hline Kuehr3-R ${ }^{\dagger}$ & ATTWTAGAGAAGGCTTCAAGATTCC & & \\
\hline Rd1LRR_F $F^{+}$ & AGGCTTCAACAATTGCC & 62 (variable, 245-381) & Distinct fragment for each of the nine muRdr1 family \\
\hline $\operatorname{Rd} 1 \mathrm{LRR} \_\mathrm{R}^{\dagger}$ & GGAATTTCACTTCCAGGA & & \\
\hline Cons cDNA-B & TCCATTCCAGAGGTGATCAAT & $56(1700)$ & Specific to the muRdr1A, $C, H$, and $I$ \\
\hline Cons cDNA-F1 & GCTGGATGGACTTCAAAGG & & \\
\hline
\end{tabular}

${ }^{\text {t}}$ These primers were also used in the expression analysis of the TNL genes. 